\title{
Analysis of the Adaptation of Urban Outdoor Public Space to the Senior Citizens Based on the Local Cultural and Artistic Characteristics in Tianjin
}

\author{
Yan Zhao, a and Wei $\mathrm{Li}^{2, \mathrm{~b}}$ \\ ${ }^{1}$ Tianjin University Renai College, China \\ ${ }^{2}$ Tianjin University, China \\ azhaoyanhit@sina.com, ${ }^{b}$ liweiwork@tju.edu.cn
}

\begin{abstract}
Keywords: local cultural characteristics of Tianjin, urban outdoor public space, analysis of the
\end{abstract} adaptation to the senior citizens

\begin{abstract}
The urban outdoor public space adapted to the senior citizens based on the local cultural characteristics in Tianjin serves as the "container" of the urban social life. It can lead the senior citizens to establish a positive idea of life in a scientific way and support the senior citizens to live the "true life" of high quality through the environment featuring complete functions and pleasant designs. Through the five cases of outdoor public space boasting the typical local cultural and artistic characteristics of Tianjin, the paper makes a survey on the activities of the senior citizens and a quantitative analysis of the adaptation of the space environment and puts forward that the key factors of the adaptation of outdoor public space to the senior citizens include the public service system for them, humanized functions and local culture and that the factors of vegetation, soil and ecological community and aquatic eco-factors also have an active impact on the adaptation of outdoor public space to them. It concurrently offers some proposals for the culture modeling and humanized transformation of the outdoor public space in Tianjin.
\end{abstract}

\section{Previous studies}

\subsection{On the relationship of the local culture and urban design}

There is plenty of research literature on the relationship between local culture and space. In his masterpiece L' Architettura della Città, Aldo Rossi, from the perspective of typology, stressed the form of urban architecture and the continuity of history, expounded that the city was the carrier of both the real life and the history and connected the individuals with the history of cities and the architecture behaviors with the urban collective memory through analogy. He put forth that cities were the places of "collective memory" and the cities' memory was manifested in the continuity of the materials and culture of the cities and people's identification with the urban culture. The research literature on the local culture and urban space design chiefly includes: The Development of the City of Tianjin written by Guo Fengqi, in which he pointed out that almost all the people in Tianjin were immigrants and therefore Tianjin was not alien to the foreign factors but conversely developed a sense of identification with them; Luo Shuwei, in his article On the Relationship between the Haihe River and the History and Culture of Tianjin, cleared his view that Tianjin's growth benefited from the Haihe River and the local culture of Tianjin reflected the tolerant and diverse nature of the Haihe River; Tan Mingyang, in his paper On the Application of the Local culture in Space Design, brought forth the idea of integrating the urban space design with material and spiritual conditions and foreign advanced cultural and technological conditions; Bi Liuju, in his article On the Inclusiveness of the Local culture of Tianjin Based on the Characteristics of Architectural Decoration of Old Town "Tongqingli" in Tianjin, analyzed that the City of Tianjin displayed the inclusiveness of the local culture featuring "perfect matching between East and West and between South and North”. 


\subsection{On the design and theory of space design adapted to the senior citizens}

The western academia conducted research on the senior citizens much earlier. Starting from the residential environment, they analyzed the advantages of the senior citizens spending their later years in their former residence and discussed the principle of comfortable environmental design adapted to the aged etc. China started later in the theoretical research on the aging society and the aging population but has yielded some achievements. However, most of the theoretical exploration and practice focus on the introduction and analysis of the basic theories and cases relating to the architectural and environmental design adapted to the senior citizens. The representative works include The Endowment Facilities and Residential Buildings for the Senior Citizens and New Trend of the Design of Congregate Housing and Accommodation for Senior Citizens in Japan by Professor Zhou Yanmin of Tsinghua University, Humanized Design of the Nursing Home Based on the Research on Physiological and Psychological Needs by Chi Xiangzheng of Tianjin University and Architecture Adaptable to the Senior Citizens-Research on Architectural Design edited by Liu Jun and Li Honglin in 2013. Nevertheless, almost no achievement has been made in the research on the space adaptable to the senior citizens based on the research on "local culture", aiming to integrate the intangible "local culture" with the tangible "urban outdoor public space" and oriented by the operability of integrating theory with practice.

\section{Research design}

\subsection{Research object}

The "homeland, hometown and old friends" can most directly and warmly reflect the spiritual emotions of the senior citizens and they cherish deeply emotional complexes for the traditional local culture. Researching the urban public space in Tianjin with local cultural and artistic characteristics, the paper researches the adaptation of the space and scenery environment to the senior citizens and aims to design the urban public space to be really humanized space for "the senior citizens to enjoy tourism, productive aging, usefulness and pleasure". Thanks to its unique geological position and historical deposits, Tianjin has developed its abundant and characteristic urban cultural system and fostered distinctive types of urban culture, such as the traditional gardens culture, the Haihe culture, the folk culture, the borrowed culture, the urban culture and the treaty ports culture. For this reason, the local cultural system of Tianjin should be highlighted in the sampling of the outdoor space with the local cultural and artistic characteristics of Tianjin. The investigation primarily sampled totally 10 groups of cases, namely, the characteristic traditional commercial area, the Historical City Core Building, the Haihe river section, the traditional parks, the traditional communities, the leased territories, the leased parks, the modern commercial area, the modern urban public service facilities, the modern parks and the modern communities. After the investigation and analysis of the 10 groups of cases among the senior citizens, the paper concluded the five groups of typical cases that could most represent the local culture of Tianjin, namely, the Tianjin Ancient Culture Street, the Italian Style Area at the Fifth Avenue, the Drum Tower Commercial Street, the Tianjin Cultural Center and the Haihe Cultural Square in sequence.

\subsection{Basic data acquisition}

Through the field research on the five parts of the outdoor public space with the typical local cultural and artistic characteristics of Tianjin, this paper makes a qualitative and quantitative analysis of the 17 indexes from such seven dimensions as the basic attributes of the senior citizens, the public service system adapted to the senior citizens, humanized functions (human health and wellbeing), local culture (protection and education of traditional culture), vegetation, soil and ecological community and aquatic ecosystem and conducts a basic comparison of the seven basic data of the area. 


\subsection{Investigations on the activities of the senior citizens}

The investigation result indicates that the senior citizens prefer to join cultural and recreational activities in larger public space such as traditional commercial streets and cultural centers to the Haihe Cultural Square and the Italian Style Area. They participate in the abundant cultural and body-building activities in traditional commercial streets. For instance, the Drum Tower Commercial Street, one of the three treasures of Tianjin, features the distinctive traditional commercial culture, folk art culture and folk culture and is one of the typical carriers of the deep emotions of the senior citizens for the traditional culture. The interview shows that the Drum Tower Commercial Area features club houses, chess, dramas and tea culture, offers various places for the activities, rest and entertainment of the senior citizens and enriches their daily life. Nevertheless, the facilities for outdoor activities are relatively inadequate, the materials of the ground surface of the streets are not anti-slippery and the children and the senior citizens often fall down on rainy and snowy days. Besides, the greening vegetation is scarcely maintained around the drum tower and most of the senior citizens think that they can't be delighted by it. The Tianjin Cultural Center is the largest urban public cultural service facility in Tianjin. Integrating all sorts of cultural pavilions, cultural squares, business and entertainment centers and youth activity centers, it is the central area for cultural exhibition, cultural exchanges, entertainment and consumption and concurrently the largest cultural and entertainment center of its kind nationwide. The investigation also indicates that the senior citizens are quite satisfied with the positioning of the functions of the cultural centers which can represent the image of Tianjin. However, it is still confronted with the problems of a low utilization rate, less empty space, insufficient safety guarantee for the facilities adapted to the senior citizens, inadequate maintenance and ineffective shading because of the greening vegetation dominated by lawn and low shrubbery mass.

\section{Analysis of the adaptation to the senior citizens}

The questionnaire method was applied to make a quantitative research on the five typical sorts of outdoor public space with the local cultural and artistic characteristics of Tianjin. The assessment factors of the questionnaire are composed of the analysis of the basic attributes of the senior citizens (the type, physical conditions, neighborhood relationship and travel range), the public service system adapted to the senior citizens (facilities adapted to the senior citizens, health and body-building facilities, entertainment facilities, emergency facilities and degree of satisfaction), the humanized functions (non-barrier design, site utilization rate, material properties, illumination and degree of satisfaction), the vegetation, soil and ecological community (greening rate, shading, feast for the eyes and degree of satisfaction), the aquatic ecosystem (travel rate on rainy days, excess water section at the site and degree of satisfaction) and the local culture (landform of streets, surrounding environment, local characteristics, cultural activities and degree of satisfaction). Totally 1,000 questionnaires were handed out for the investigation with 974 valid copies collected, accounting for $97.4 \%$.

The findings show that the public service system adapted to the senior citizens, the humanized functions and the local cultural factors are the key factors of the outdoor public space adapted to the senior citizens. Among the five typical cases, $60 \%$ of the senior citizens are satisfied with the places and facilities for their communication and activities while the rest $40 \%$ hold the view that the public space has not provided corresponding services for them. A great majority of the cases do not have complete emergency facilities adapted to the senior citizens. The public service system adapted to the senior citizens is a key factor to boost the adaptation of the urban public space to the senior citizens. Greater efforts should be made to boost the quality of the characteristic public space in Tianjin.

The local culture is the core element of the adaptation of the urban outdoor public space to the senior citizens, whose profound deposits can arouse the historical memory and emotions of the senior citizens from the spiritual perspective and benefit the physical and mental health of the senior 
citizens. The degrees of satisfaction with the cultural quality are respectively $56 \%$ with the ancient cultural street, 33.3\% with the Italian Style Area, 28.4\% with the Tianjin Cultural Center, 27.6\% with the Drum Tower Commercial Street and $\mathbf{1 7 . 3 \%}$ with the Haihe Square. It can thus be seen that the commercial ports culture, the folk culture, the leasing culture and the traditional culture can arouse a profound sense of identification among the senior citizens and it boasts great practical significance to fully excavate the local cultural characteristics of Tianjin and materialize them in the urban open space.

The degrees of satisfaction of the senior citizens with the greening and vegetation of the sites are in sequence 35.8\% with the Tianjin Cultural Center, 34\% with the Ancient Cultural Street, 25\% with the Drum Tower Commercial Street, 23.3\% with the Haihe Square and 18.9\% with the Italian Style Area. Most senior citizens think it is not pleasing for the eyes because the planting at some sites has not been done in a proper order and public greening severely lacks effective maintenance. Therefore, the physiological needs of the senior citizens should be fundamentally considered to create the comfortable, reasonable and pleasing planting environment.

The travel rate of the senior citizens is quite low on rainy days and most areas suffer from waterlogging or low inconvenient travel rates on the rainy days to different extent, namely, $78 \%$ in the Ancient Cultural Street, $44.8 \%$ at the Tianjin Cultural Center, $43.9 \%$ on the Haihe Square, $41.3 \%$ in the Drum Tower Commercial Street and 13.3\% in the Italian Style Area in sequence. It is highly advised to adopt the technical skills of low-influence development to create the sponge urban public space and environment.

\section{Strategies to adaptation to senior citizens}

\subsection{Establishing the public service facility network adaptable to the senior citizens and optimizing their way of travel.}

The senior citizens often go to such urban public space as the neighborhood communities, streets, parks, living facilities, commercial facilities and campuses etc. Efforts should be made to establish the hierarchical public service facility network adaptable to the senior citizens and solve the macrocosmic and microcosmic problems for them such as difficult travel in the urban public space in Tianjin, incomplete facilities for senior citizens, insufficient activity space and unreasonable space design. The urban public service facility network adaptable to them in Tianjin comprises the site public service facilities, the slow travel traffic system and the surrounding linked corridor network adaptable to the senior citizens. The public service facilities in the area refer to the complete facilities, the health and body-building facilities, the entertainment facilities and the emergency facilities built in the area adaptable to the senior citizens; the slow travel traffic system refers to the system for slow traffic, namely, public transportation, walking, jogging and cycling built surrounding the communities to facilitate the travel of the senior citizens; the surrounding linked corridor network is the green slow travel traffic linking the public service facilities surrounding the living area of the senior citizens.

\subsection{Innovating the urban green plants and landscape design approach and making the senior citizens sound in mind and health.}

The investigation shows that green planting universally suffers the problems of limited amount, single variety, bad shading and low ornamental value. The space layout for green plants should try to meet the physiological needs of the senior citizens, plant more deciduous trees of large crowns and perfect shading in the sitting area and shallow-bed plants accessible for the senior citizens, activate the five senses of the senior citizens to experience the scenery of green plants, make the best of the functions of the plants in purifying the air and giving out health type materials and give play to the effects of the horticultural therapy of gardening. 


\subsection{Completing and restoring the urban ecology background and creating the sound environment for the senior citizens.}

Endeavors should be made to complete the construction of the sponge city in the outdoor public space in Tianjin and apply the technical measures of low influence upon development to restore the urban ecology background. To address the problems of difficult travel on rainy days and serious waterlogging during the pavement in the investigation, the green area and permeable pavement can be added in the public space to improve the function of natural infiltration of the rainwater at the site; the rainwater collection devices should be used or the rainwater garden should be designed to collect and purify the rainwater and make waste profitable; grassed swales should be set to transfer and detain the rainwater at the intersection of the soft and hard landscape and the interactive landscape devices between the senior citizens and the rainwater landscape should be designed, for instance, infiltration tree chairs to collect and purify the rainwater and serve as recreational facilities.

\subsection{Reasonably organizing characteristic cultural and recreational activities according to the psychological characteristics.}

According to Abraham Maslow's theory, the hierarchiy of needs of the senior citizens can be generalized to be physiological needs, safety needs, social needs, esteem needs and self-realization. Efforts should be delivered to improve the characteristic public space environment of Tianjin to satisfy the behavior demands of the senior citizens. Their physiological demands for learning, communication, body-building and self-cultivation should be satisfied in the area; the non-barrier design and the simple evacuation streamline should be considered to improve the comfort of design and meet their safety needs; their social needs should be realized from the perspective of interaction between the nature and the city, for instance, building gardens so that the senior citizens can enjoy the fun of planting and organizing characteristic cultural and recreational activities in Tianjin to satisfy their spiritual needs to participate in the social life; pleasant private or semi-private space for communication shuld be created for the senior citizens in the area to gratify their esteem needs; their needs for self-realization should be met on the basis of the satisfaction of the above demands.

\subsection{Inheriting and carrying forward the cultural and artistic characteristics of Tianjin and enhancing the profound emotions and memory of the senior citizens.}

The culture of Tianjin boasts abundant and long connotations and features reflected in urban construction, business, food, housing, etiquette and folk customs. Deeply rooted in the memory of the senior citizens in Tianjin, it vastly influences the city life of the Tianjinese. Organizing and creating distinctive and diverse cultural activities including Chinese folk art forms, painting, dancing and folk performances in the characteristic urban public space in Tianjin is favorable to arouse the most cherished cultural memory of the senior citizens and boasts uncommon practical significance to inherit and carry forward the characteristic culture of Tianjin.

\section{References}

[1] Jeffrey Anderzhon[et al.]. Design for Aging: International case studies of building and Program. John Wiley \&Sons,Inc.2012: 233-241

[2] AIA Design for Aging Knowledge Community (DFA),Perkins Eastman Research Collaborative. Design for Aging Review 10: Insights and Innovations: The State of Senior Housing . Published \& professionally reviewed by:The American Institute of Architects.2010: 13-14

[3] Yuan Yiqian, LiLei, LiWei. New Hybrid Community: A Housing Model Fit for the Psychological Needs of the Senior[J]. Urbanism and Architecture, 2014 (2) 142-145

[4] Jin Jun, Qi Kang, BAI Lu-Fel, SHEN Xiao-qian. The Investigation and Analysis of the Fitness to the Aged of Micro-space in Old Town Based on the Livable Target-With the Example of Nanjing Xinjiekou Subdistrict[J].Chinese landscape Arichtecture, 2015（3）91-95 